\title{
Poesía, género y educación: de Mistral y Storni a Luque, Lanseros y Berbel
}

\author{
Patricia Martínez León \\ Universitat de València, Grupo Elcis
}

Resumen: La poesía escrita por mujeres en español no ha obtenido en el currículum ni en los libros de texto de Secundaria el espacio que merecería. Por ello en este trabajo presentamos una propuesta didáctica para acercarla a los estudiantes de último curso, que persigue, además, propiciar una fértil reflexión en torno a tópicos de género diversos, su formación en calidad de lectores críticos, una iniciación a la escritura creativa y una construcción reflexiva de sus identidades genéricas. Previamente realizamos una breve introducción teórica en la que analizamos los factores conducentes a la relegación de la poesía en Secundaria, las prácticas que se aconsejan y desaconsejan para una educación poética exitosa, la exclusión histórica de las mujeres del canon y la importancia de su inclusión o el fenómeno del reciente boom de la poesía escrita por mujeres en español y de las poetas best seller y sus implicaciones educativas.

Palabras clave: educación literaria, poesía, género, identidad, canon.

\section{Poetry, gender, and education: from Mistral and Storni to Luque, Lanseros, and Berbel}

Abstract: Poetry written by women in Spanish has not been given the space it deserves on the curriculum or in secondary school textbooks. In this work, we present a teaching proposal to bring such works closer to final-year students, as well as encourage a productive reflection on various gender topics. This proposal offers a training for critical reading and encourages creative writing and a reflective construction on gender identities. In the first place, we give a brief theoretical introduction on the factors that led to the relegation of poetry in secondary schools, the historical exclusion of women from reading lists and the importance of their inclusion, the practices that are recommended and discouraged for a successful poetic education, and the recent boom in poetry written by women in Spanish, as well as best-selling poets, and the educational implications.

Keywords: Literary Education, Poetry, Gender, Identity, Reading Lists. 


\section{Introducción}

$\mathrm{P}$

oesía y mujer han constituido dos géneros (literario el uno, humano el otro) históricamente relegados, por lo que cabía esperar que la poesía escrita por mujeres heredase la condición de literatura sumergida. Por otra parte, la etapa de Educación Secundaria coincide con un momento clave en la formación integral de los seres humanos y en los procesos de construcción identitaria de estos, que poseen una naturaleza eminentemente discursiva (y por tanto la recepción y la producción literarias tienen una potencial incidencia en los mismos). Por último, pese a las innegables conquistas en materia de género, es también incontestable que persisten las desigualdades a este respecto en la actualidad y ello hace especialmente necesaria la reflexión en torno a tópicos de género y el aporte de mujeres que sirvan de referentes intelectuales (en este caso, poetas) a los adolescentes.

Este trabajo pretende servir de propuesta para acercar las mujeres poetas, la poesía escrita por mujeres y la educación poética a los estudiantes de Secundaria, partiendo de un análisis de los factores conducentes a la relegación de la poesía en la Educación Secundaria, de las prácticas que se aconsejan y desaconsejan para una educación poética que favorezca la posibilidad de que los alumnos aprecien este género literario, de la exclusión histórica de las mujeres del canon y del campo literario y de los motivos de la importancia de su inclusión o en torno al fenómeno del relativamente reciente boom de la poesía escrita por mujeres en español y de las poetas best seller y sus implicaciones educativas.

Tras el desarrollo de estos apartados dedicados a una breve pero necesaria introducción teórica, presentamos una propuesta didáctica dirigida al último curso de Secundaria que tiene por objetivos favorecer el acercamiento de los alumnos a un corpus de poesía escrita por mujeres en español que propicie una fértil reflexión en torno a tópicos de género diversos, su formación en calidad de lectores críticos y una iniciación a la escritura poética, que esperamos que contribuyan, al tiempo, a una construcción crítica de sus identidades genéricas en una etapa decisiva. 


\section{Factores conducentes a la relegación de la poesía en la} enseñanza Secundaria

Los factores que conducen a la relegación de la poesía en general en la Educación Secundaria y muy especialmente de la poesía escrita por mujeres son diversos: prejuicios en torno a este género literario, un enfoque metodológico convertido en obstáculo, la escasa representación de la poesía en el currículum o la no incorporación de la poesía escrita por mujeres en los manuales escolares. A continuación nos detendremos mínimamente en ellos.

Entre los prejuicios extendidos en torno al género poético, Adricaín y Rodríguez (2016) destacan la estereotipación del poeta como un intelectual romántico, ajeno a la realidad, la consideración machista de la lírica como género exclusivamente femenino o el mito de la ininteligibilidad de la poesía. Pero no menos importancia conceden en el distanciamiento de los alumnos de la poesía a un enfoque metodológico inadecuado basado en el estudio y la lectura obligatoria de poetas canónicos alejados de la sensibilidad de los estudiantes o a la falta de preparación, de convencimiento o de entusiasmo por parte de los docentes para actuar como mediadores entre discentes y poesía.

¿Y qué hay de las actitudes de los adolescentes hacia la poesía? A este respecto el estudio de Zaldívar (2017) revela el predominio de la preferencia por otros géneros entre los adolescentes, así como su acercamiento al género poético fundamentalmente a través de letras de canciones. ¿Pero qué se esconde tras ese distanciamiento? De nuevo el predominio de un modelo historicista, teórico y memorístico en la didáctica de la poesía, que debiera ser sustituido por la lectura conjunta en el aula, la conversación literaria, la escritura creativa, la educación emocional o la vinculación de la poesía con la realidad y la experiencia personal, la música y las formas de poesía no canónicas, a juicio de Zaldívar (2017).

Por otra parte, en lo concerniente a la relegación de la poesía escrita por mujeres, cabe mencionar los criterios patriarcales en la elaboración de los manuales escolares, cuyos responsables se guiarían en muchas ocasiones por selecciones de autores realizadas en antologías publicadas en editoriales prestigiosas, en donde las autoras estarían ausentes o escasamente representadas y, como consecuencia, esa ausencia se trasladaría también a los manuales. Así, diversas autoras dan cuenta de esa falta de representación 
prácticamente total de las mujeres en los libros de texto y en el currículo de Educación Secundaria y Bachillerato (Lasa, 2016; López Navajas, 2014; Sánchez García, 2019).

Por último, pero no menos importante, la escasa presencia de la poesía en el currículum de Secundaria (en nuestro caso, de la Comunidad Valenciana), que se restringe casi exclusivamente al «reconocimiento de las características propias de los géneros literarios a partir de una selección de textos en prosa y en verso", a lo que se añaden la comprensión y producción de adivinanzas y poemas descriptivos y los temas, formas, tendencias y principales escuelas de la lírica en los dos últimos cursos (Decret 87/2015, de 5 de juny, del Consell).

\section{Educación literaria y educación poética}

Para avanzar desde las prácticas desaconsejadas en la didáctica de la poesía hacia un enfoque con mayores expectativas de éxito, habremos de hablar de educación poética. Pero antes de detenernos específicamente en esta, hemos de referirnos necesariamente al cambio de perspectiva supuesto por la educación literaria, decisivo en la enseñanza de la literatura. Esta, sin desatender los planos de autor y obra, enfatizados en anteriores orientaciones, se centra principalmente en las necesidades formativas de los discentes, con el objetivo de formar lectores competentes, capaces de comprender, disfrutar y también crear textos literarios.

La educación literaria comporta la superación de un historicismo positivista, pero se vale de la historia de la literatura ante la contextualización y comprensión textuales y abre un espacio en esa historia a la figura del lector, que, a través del juicio realizado de las obras leídas, se concibe como mediador de la producción literaria de los autores.

Sobre la base de la importancia del fundamento científico que proporcionan los estudios literarios, podemos apreciar la valiosa herencia de la estética de la recepción y la apertura con esta del texto a la subjetividad del lector o las contribuciones de la literatura comparada a la didáctica de la literatura: desde la constante del diálogo entre producción y recepción, entre literaturas o entre discursos creativos; pasando por el cuestionamiento del canon; hasta el entendimiento de la lectura como un ejercicio comparativo, en el que cada 
texto se interrelaciona con otros y es interpretado a la luz de esas conexiones puestas de manifiesto, para alcanzar una comprensión más profunda (Ballester, 2015; Colomer, 1998; Mendoza, 1998; Núñez, 1998).

En particular, durante la escolaridad obligatoria, perseguimos la consecución progresiva por parte del alumnado de una expresión, comprensión y producción desenvueltas, en sistemas verbales y no verbales, optando por la heterodoxia didáctica y por un corpus amplio, plural, interdisciplinar e intercultural (que dé cabida a diversidad de literaturas y lenguajes estéticos) y potenciando el carácter autónomo de discente y docente.

Ese carácter autónomo del discente entronca con una cuestión clave como es el entendimiento de la lectura en términos de un intercambio simbólico, un diálogo entre el texto y el lector. De modo que no es concebible la acción de leer sin la participación del receptor en la construcción de significado (Ballester, 2015; Ballester e Ibarra, 2009; Colomer, 1998; Jover, 2008; Mendoza, 1998; Núñez, 1998).

Creemos que puede ser conclusiva en este punto la síntesis de Prado (2004) en cuanto a las que serían las bases científicas de la educación literaria: las ideas constructivistas, que colocan al lector en la posición de constructor de sentido del texto; las ideas desprendidas de la teoría de la recepción que, poniendo el foco en el acto de lectura, coinciden en el papel decisivo del mismo en un proceso de interacción con el texto mediante el que le confiere sentido; y las proporcionadas por la semiótica y, en particular, la pragmática del texto, entendiendo el texto literario como un signo indisociable de una función comunicativa, enmarcada en diferentes contextos.

Asimismo, coincidimos con Bombini (2008) en las cuatro vías fundamentales que propone para repensar las prácticas de aula desde un paralelo replanteamiento de la teoría que las sustenta: rescatar (sin retroceder al enciclopedismo) la dimensión histórica en la conceptualización, la lectura y la discusión de lo literario; habilitar la relación entre esta, la retórica propia del texto literario y las operaciones hermenéuticas del lector en la construcción de significado; entender la lengua literaria como un espacio de experimentación estética y verbal; y convertir las prácticas de lectura y escritura en objeto de estudio y eje de la enseñanza. 
Y bien, la educación poética, en el marco de la literaria, comparte con esta el objetivo de formar lectores competentes, que adquieran el gusto por la obra literaria y se abastezcan de herramientas para enfrentarse a textos de complejidad creciente por medio del acceso a una sucesión ordenada de conocimientos y experiencias literarias. No obstante, serán específicas la brevedad, la intensificación y condensación del lenguaje, la voluntad de forma, el ritmo perceptible y la tonalidad emotiva como características del poema.

En esta línea, el lenguaje poético (con la clasificación y descripción de figuras estilísticas que afectan a los niveles fónico, morfológico, sintáctico, semántico y léxico), los modelos estructurales más frecuentes en la construcción del poema, el tipo de locutor y su relación con el tono o la diferenciación entre los receptores reales y los poemáticos constituirán algunos de esos conocimientos, ilustrados siempre mediante la ejemplificación (aportada por el docente o resultante de la búsqueda por parte de los estudiantes).

No obstante, en cuanto al esbozo de una suerte de metodología adecuada a la enseñanza/aprendizaje de la poesía parece deseable que venga introducida más por la exploración de cuanto sugiere o hace sentir o pensar el poema a los lectores, es decir, por la verbalización de la propia experiencia lectora, que por el análisis de los medios formales y conceptuales.

Sobre la importancia de no instrumentalizar la poesía y sobre el valor de su capacidad sugestiva y la riqueza de su polisemia se expresan atinadamente en las siguientes líneas Adricaín y Rodríguez (2016: 18-19):

El cúmulo de impresiones, de preguntas, de sensaciones y conceptos que suscita la lectura de esos versos, es todo lo que entrega el poema por el esfuerzo de leerlo. Ese poema nos da, en trueque, en pago por haberlo leído, algo inasible, difícil de explicar, inapresable, algo muy poco práctico en la medida que no enseña nada explícitamente, pues solo inquieta, sugiere, nos intranquiliza con relación a nuestro estado en el instante anterior a la lectura. Ese algo es mucho o poco, según se mire, según la sensibilidad y la razón de cada cual.

La selección del corpus por parte del docente (basada en criterios de calidad artística y pluralidad estética y ética, a los que se pueden sumar otros como los temáticos o la potencialidad reflexiva) se convierte en una cuestión clave y, una vez escogidos los textos, la lectura y el comentario de poe- 
mas en voz alta (que permite enfatizar la lectura interpretativa a través de la construcción compartida de significados múltiples), la lectura de distintos tratamientos líricos de un mismo tema, los juegos de escritura creativa o el trabajo de contextualización e investigación son algunas de las posibilidades didácticas más recomendadas, apartándonos de un criticado enfoque historicista (Adricaín y Rodríguez, 2016; Cerrillo y Luján, 2010; Sánchez García, 2019).

Y para que los alumnos puedan actualizar los textos poéticos que les proporcionamos estos habrán de ser, además de los clásicos, también contemporáneos, incluyendo en el canon, por qué no, la poesía experimental, la digital, la visual o la sonora, en forma de textos multimodales (Bordons, 2016; Pérez Parejo, 2010; Quiles, 2020; Zaldívar, 2017).

Por otro lado, el rol del docente habrá de ser también repensado, pasando de concebirse como legitimador de interpretaciones a entenderse como un colaborador más en la construcción de sentido por parte de los alumnos (Jean, 1996; Solustri, 2018).

\section{La exclusión de las mujeres del canon o su relegación a la condición de literatura sumergida}

El papel de la alfabetización y del acceso al mundo cultural en la emancipación y la conquista de autonomía por parte de las mujeres ha sido y es incontestable, convirtiéndose la lectura y la escritura en prácticas liberadoras y empoderadoras, en la lucha contra la subordinación y la desigualdad históricamente padecidas (Aguilar, 2008; Bollmann, 2006; Showalter, 2010; Tusquets, 2006).

Si bien sea cierto que en la actualidad las lectoras superen en número a los lectores, siguen siendo ellos quienes más publican en las editoriales de prestigio y quienes más presentes están en antologías poéticas y manuales escolares.

Los prejuicios y estereotipos asociados a la poesía escrita por mujeres (sufrimiento amoroso como tema predominante, sensiblería o ausencia de calidad estética), más allá de lo anterior, no han ayudado a mejorar la situación, aunque la diversificación de los temas sea cada vez más evidente (Cánovas, 2018; Hermosilla, 2011; Pérez Parejo, 2010). 
Coincidimos con Cabré (2013: 297-313) en que la cuestión del canon no es en absoluto insustancial, pues «es el resultado de la necesidad de legitimar el poder y de justificar con ello la sumisión. Quienes hacen el canon son los guardianes de la cultura oficial y tienen mucho interés en que este perviva dentro de unas fronteras bien delimitadas».

Como también sostiene Sánchez García (2017), la ideología condiciona enormemente la constitución de cualquier canon y subyace a la decisión de qué obras cumplen los criterios de calidad estética, cuándo y cómo se publican y, en este sentido, ha venido excluyendo de los cauces tradicionales de la distribución editorial y de las antologías (a veces en antojo-logías) la literatura escrita por mujeres, convirtiéndola en una suerte de literatura sumergida.

Más allá de esta inercia interesada, el canon debería avanzar, a juicio de esta autora y al nuestro, hacia la apertura, la pluralidad de voces y la suma de elecciones para la determinación de referentes valiosos, con espacio para las mujeres por la calidad artística de su escritura, desde una ideología no totalitaria ni patriarcal.

Otras autoras nos alumbran alrededor de las consecuencias de un canon literario androcéntrico, patriarcal y misógino, con escasa presencia de obras escritas por mujeres, así como de las responsabilidades que a este respecto se nos derivarían a los docentes. En esta línea, exponen cómo un canon literario de tales características redunda en la universalización de la mirada masculina (desde la que, de este modo, se construyen los modelos sociales con que se verán confrontadas las mujeres), contribuye a normalizar la misoginia y supone, además, la ausencia de referentes femeninos de realización intelectual y artística.

Y es que, tal y como explica Servén (2008: 9-10), no podemos obviar la función axiológica de la obra literaria:

Hoy el canon es, por tanto, objeto de debate. Puesto que la obra literaria es creación verbal, el pensamiento que se expresa es en ella inseparable del lenguaje que usa y que es portador de los valores propios de la sociedad que lo genera. Así, la obra literaria presenta una función estética, una función gnoseológica -puesto que constituye una forma de conocimiento y comprensión de la realidad- y una función axiológica -porque nos trasmite un sistema de valores. De este modo, la literatura se ha convertido 
en transmisora de unos modelos de feminidad, de acuerdo con las pautas de la ideología de donde emerge; y contribuye a la permanencia de ciertos valores por medio de obras maestras en virtud del poder educativo del arte.

Ello hace necesarios el cuestionamiento del canon (interrogando las valoraciones ideológicas y de género subyacentes a su constitución), la superación de sus distorsiones sexistas, y la incorporación de obras escritas por mujeres sobre la base de la calidad estética de estas.

A este respecto, nos adherimos a los fines que Reyzábal (2012: 22) explicita en su propuesta de revisión del canon literario:

a) desenmascarar la idea implícita en el canon vigente de que la expresión literaria de la mujer ha sido minoritaria y marginal; b) redescubrir muchas voces femeninas silenciadas, dando la posibilidad de abrir el currículo escolar o universitario a nuevas propuestas de análisis que permitan reconsiderar (mediante la recuperación de textos ignorados hasta ahora) si se mantienen como referente los mismos hitos literarios o si, por el contrario, se sustituyen o amplían con otros en los que tenga cabida la voz femenina; c) alertar a las nuevas generaciones sobre los factores de discriminación existentes en la selección de modelos estéticos, fomentando así su capacidad crítica; d) animar a las mujeres de hoy a encontrar sus cauces expresivos propios, aportándoles modelos (vitales y estéticos) en femenino que les permitan construir su identidad de género y proyección estética al margen de tópicos interesadamente sesgados.

Benegas (2017: 388), por su parte, traslada la noción de campo social acuñada por Bourdieu, entendido como «espacio atravesado por redes de relaciones entre personas con una actividad, modos de ser y de actuar en común, que a su vez defienden esa producción ante la sociedad» al campo literario y se vale de ella para explicar la maniobra de exclusión de las mujeres escritoras de antologías canónicas, premios, subvenciones o cargos. Señala, asimismo, la selección de un número muy reducido de escritoras como origen de disputas entre las mismas, que hace necesaria, por contra, la generación de vínculos entre estas y su completa inclusión en el campo literario. 


\section{En torno al boom de la poesía escrita por mujeres en español y las poetas best seller}

En la primera mitad del siglo XXI la poesía se ha convertido en un auténtico fenómeno de masas. Con la aparición de una creciente nómina de autoras se consolida el denominado boom de la poesía escrita por mujeres en español. Una poesía caracterizada por la claridad, el estilo directo y la sencillez, confidencial, próxima, emocional e íntima (Valverde, 2017).

Está en auge la poesía en el espacio digital (blog o microblogging, sitios web personales, Twitter, Instagram, Youtube), donde publican y publicitan su obra literaria autoras en muchos casos conocidas por su trayectoria musical o por su actividad en redes y de algún modo se democratiza la palabra poética, si bien la calidad de estas creaciones sea a menudo cuestionada, como también el feminismo de su discurso (Logroño, 2019; Navarrete, 2019; Pulido, 2020; Regueiro, 2018).

Esta poesía tiende a la versificación libre y al poema en prosa, es multimodal en muchos de los casos, poetiza la vida de las autoras en algunos de ellos, sus rasgos temáticos y formales facilitan la identificación de los lectores jóvenes (amor y desamor como temas fundamentales, referencias culturales y cotidianas y lenguaje próximo a los jóvenes), así como la generación de una suerte de sentido de pertenencia grupal, hace uso de recursos como el humor, la ironía o la intertextualidad y, a la vista de su éxito, las editoriales convierten a sus seguidores en potenciales compradores de libros (Logroño, 2019; Pérez Parejo, 2010; Pulido, 2020; Regueiro, 2018).

Pero frente la emergencia de este fenómeno se desarrollan opiniones divididas, como con tino ilustra Valverde (2017: 416) en las siguientes líneas:

El boom de la poesía escrita por mujeres resulta incómodo al poder desde el que se construye el canon porque es un disparo muy poderoso a su línea de flotación. Por eso el fenómeno de la nueva poesía joven ha sido tratado por la crítica tradicional de dos maneras: el silencio o el cuestionamiento sobre si lo que escriben es poesía o no. Esa es una discusión más cómoda, sobre todo porque vuelve a situar a la élite en una posición de privilegio, la que otorga la legitimidad de decidir qué sí y qué no es poesía.

Por su parte, Regueiro (2018: 76) expresa lo siguiente al respecto: 
está claro que debe valorarse el que se haya acercado la poesía a lectores noveles que no sentían ninguna afinidad por ella. Sin embargo, queda en manos de la crítica el valorar hasta qué punto estos nuevos poetas transmiten unos mensajes positivos o [...] reproducen modelos heteropatriarcales y cosifican a la mujer; hasta qué punto esta poesía contribuye a la formación de lectores y a la educación artística y literaria, cuando no están del todo claros sus rasgos de poeticidad.

Parte de razón tienen ambos a nuestro juicio, por lo que corresponderá al docente seleccionar, de entre esa poesía joven contemporánea aquella que, sobre la base de la calidad estética, permita, a un tiempo, aproximar a los alumnos al género poético, conectar con su sensibilidad e intereses y contribuir a su educación literaria. Quizá una de las claves pueda ser tender puentes, abrir el diálogo o invitar a la comparación entre los textos de siempre y los textos de hoy.

\section{Una propuesta didáctica para la inclusión de la poesía escrita por mujeres en español en el último curso de Secundaria}

Convencidos de la importancia de la incorporación de la poesía y, en particular, de la poesía escrita por mujeres en la Educación Secundaria, en las líneas que siguen presentamos una propuesta didáctica que tiene por objetivos específicos:

1. Favorecer el acercamiento de los alumnos a un corpus de poesía escrita por mujeres en español, que, al tiempo que permita valorar su calidad estética e identificar sus rasgos de poeticidad, propicie una fértil reflexión en torno a tópicos de género diversos.

2. Favorecer la formación de los alumnos en calidad de lectores críticos a través de la construcción compartida de significados en la discusión literaria y de la contextualización y reformulación de contenidos, el reconocimiento de figuras estilísticas o la expresión de pensamientos, sentimientos y opiniones suscitados por los poemas leídos.

3. Favorecer una iniciación a la escritura poética por parte de los alumnos tomando como modelo el corpus de poemas seleccionados y los tópicos que en estos se abordan. 
En cuanto a la selección del corpus de poetas (Mistral, Storni, Luque, Lanseros y Berbel), sobre la base de la calidad estética de la poesía de las autoras escogidas, hemos tenido en cuenta el potencial de reflexión en torno a tópicos de género que ofrece su obra y la combinación de poetas contemporáneas con poetas imprescindibles del siglo XIX. Todas ellas, además, han sido galardonadas con distintos premios.

En el cuadro que sigue explicitamos la vinculación de la propuesta con el currículum de Secundaria.

\begin{tabular}{|l|}
\hline \multicolumn{1}{|c|}{$4^{\circ}$ DE ESO, LENGUA CASTELLANA Y LITERATURA } \\
\hline Contenidos \\
\hline - Escucha activa y diálogo igualitario. \\
- Lectura guiada y comprensión de obras literarias. \\
- Elaboración de trabajos personales, de creación/investigación senci- \\
lla y supervisada sobre las lecturas realizadas. \\
- Análisis sencillo de textos (contextualización y análisis temático). \\
\hline Criterios de evaluación \\
\hline - Participar activa y respetuosamente en intercambios comunicativos \\
defendiendo críticamente las opiniones propias. \\
- Realizar con sentido crítico y creatividad proyectos de trabajo indi- \\
viduales y colectivos sobre temas sociales y literarios, buscando y se- \\
leccionado información. \\
- Realizar lecturas de obras literarias. \\
\hline Estándares de aprendizaje evaluables \\
\hline - \\
Trabaja en equipo determinados aspectos de las lecturas propuestas, \\
investigando y experimentando de forma progresivamente autónoma. \\
- Redacta textos personales de intención literaria a partir de modelos \\
dados, siguiendo las convenciones del género y con intención lúdica \\
y creativa. \\
- Aporta en sus trabajos escritos u orales conclusiones y puntos de vis- \\
ta personales y críticos sobre las obras literarias expresándose con \\
rigor, claridad y coherencia. \\
\hline
\end{tabular}

Fuente: Decret 87/2015, de 5 de juny, del Consell/Real Decreto 1105/2014, de 26 de diciembre 
La propuesta didáctica diseñada está vertebrada en torno a cinco ejes temáticos que se corresponden con las cinco sesiones de cincuenta minutos de duración que la constituyen. Como puede observarse en las tablas que siguen, todas mantienen una misma estructura, basada en la discusión literaria a partir de una serie de preguntas guía, las actividades de búsqueda documental y las invitaciones a la escritura creativa a partir de consignas y modelos textuales. Todas las actividades se desarrollan en grupos de cuatro o cinco personas y posteriormente se ponen en común en el gran grupo y las sesiones siempre son inauguradas mediante la lectura en voz alta de uno o dos poemas y acompañadas de material complementario para enriquecer la discusión ampliando los conocimientos literarios, culturales o enciclopédicos.

\begin{tabular}{|c|c|}
\hline \multicolumn{2}{|c|}{$\begin{array}{c}\text { SESIÓN 1) DESIGUALDADES DE GÉNERO EN EL PASADO } \\
\text { Y EN EL PRESENTE }\end{array}$} \\
\hline Textos poéticos & $\begin{array}{l}\text { Preguntas para guiar la discusión } \\
\text { literaria }\end{array}$ \\
\hline \multirow{4}{*}{$\begin{array}{l}\text { «Una de dos», Lanseros } \\
\text { «Árbol genealógico», Berbel }\end{array}$} & $\begin{array}{l}\text { ¿De qué hablan estos poemas? ¿Qué } \\
\text { pensáis al respecto? ¿Qué os hacen } \\
\text { sentir? }\end{array}$ \\
\hline & ¿Identificáis alguna de las figuras \\
\hline & $\begin{array}{l}\text { estilísticas recopiladas y descritas en } \\
\text { el documento 1? En caso afirmativo, } \\
\text { localizadlas y explicadlas. }\end{array}$ \\
\hline & Act. de búsqueda documental \\
\hline $\begin{array}{l}\text { Material complementario para enri- } \\
\text { quecer la discusión }\end{array}$ & $\begin{array}{l}\text { Buscad información sobre la vida y } \\
\text { la obra de Raquel Lanseros y Rosa } \\
\text { Berbel y compartidla con el resto de } \\
\text { la clase. }\end{array}$ \\
\hline
\end{tabular}


Documento 1. Clasificación y descripción de figuras estilísticas (Cerrillo y Luján, 2010).

Consignas de escritura creativa Tomando como modelo los poemas leídos, componed vuestra propia poesía (de entre ocho y catorce versos) poniendo de relieve algunas desigualdades existentes entre mujeres y hombres en el pasado y/o en el presente. Podéis buscar información al respecto para documentar vuestro texto.

\begin{tabular}{|c|c|}
\hline \multicolumn{2}{|c|}{$\begin{array}{c}\text { SESIÓN 2) IMPERATIVOS SOCIALES DE FEMINIDAD } \\
\text { Y DOBLE MORAL SEXUAL }\end{array}$} \\
\hline Textos poéticos & $\begin{array}{l}\text { Preguntas para guiar la discu- } \\
\text { sión literaria }\end{array}$ \\
\hline \multirow[t]{2}{*}{$\begin{array}{l}\text { «Deseo», Berbel } \\
\text { «Tú me quieres blanca», Storni } \\
\text { «Femme fatale con prisa», Berbel }\end{array}$} & $\begin{array}{l}\text { ¿Qué temas se abordan en } \\
\text { estos poemas? ¿Qué ideas y } \\
\text { opiniones os suscitan? } \\
\text { ¿Identificáis alguna de las } \\
\text { figuras estilísticas recopiladas } \\
\text { y descritas en el documento } 1 \text { ? } \\
\text { En caso afirmativo, localizadlas } \\
\text { y explicadlas. }\end{array}$ \\
\hline & $\begin{array}{l}\text { Actividades de búsqueda } \\
\text { documental }\end{array}$ \\
\hline $\begin{array}{l}\text { Material complementario para enriquecer } \\
\text { la discusión }\end{array}$ & $\begin{array}{l}\text { Buscad información sobre la } \\
\text { vida y obra de Alfonsina Stor- } \\
\text { ni y compartidla con el resto } \\
\text { de la clase. }\end{array}$ \\
\hline
\end{tabular}


Documento 1. Clasificación y descripción de figuras estilísticas (Cerrillo y Luján, 2010).

Sexo: la mala educación (Salvados. Temporada 14).
Consignas de escritura creativa

Escoged alguno de los tópicos debatidos en la discusión generada a partir de la lectura de los poemas y componed vuestra propia poesía (de entre ocho y catorce versos) en torno al mismo.

\section{SESIÓN 3) VIOLENCIA DE GÉNERO Y ABUSO SEXUAL}

Textos poéticos

Preguntas para guiar la discusión literaria

¿Cuál es el tema del que se habla en cada una de las partes (I, II) de este poema? ¿Qué os ha hecho sentir?

¿Identificáis alguna de las

«Las niñas siempre dicen la verdad», Berbel figuras estilísticas recopiladas y descritas en el documento 1 ? En caso afirmativo, localizadlas y explicadlas.

Actividades de búsqueda documental

¿Qué es la violencia de

Material complementario para enriquecer género? ¿Qué tipos de violencia de género existen y en qué la discusión consisten? Buscad información al respecto y compartidla con el resto de la clase. 
Documento 1. Clasificación y descripción de figuras estilísticas (Cerrillo y Luján, 2010).

Cortometraje Amores que matan (Bollaín, 2000).

Cuadro explicativo sobre los tipos de violencia de género (Moriana, 2017).

Consignas de escritura creativa

Escribid un poema (de entre ocho y catorce versos) que tenga por tema la violencia de género en cualquiera de sus formas.

\section{SESIÓN 4) MATERNIDAD}

Textos poéticos

Preguntas para guiar la discusión literaria

¿De qué hablan estos poemas? ¿Cómo expresaríais el contenido con vuestras palabras? ¿Qué os hacen sentir?

«La mujer estéril», Mistral

¿Identificáis alguna de las fi«No-mo», Berbel guras estilísticas recopiladas y descritas en el documento 1 ? En caso afirmativo, localizadlas y explicadlas.

Actividades de búsqueda documental

Buscad información sobre la

Material complementario para enriquecer la discusión vida y obra de Gabriela Mistral y compartidla con el resto de la clase. 
Documento 1. Clasificación y descripción de figuras estilísticas (Cerrillo y Luján, 2010).

Roedores: cuerpo de embarazada sin embrión (Bonet, 2018).

\section{SESIÓN 5) POESÍA AUTOBIOGRÁFICA}

Textos poéticos

«Yo quería ser Jo o los tres elixires de Miss Alcott», Luque

«Promesas que cumplir», Lanseros
Consignas de escritura creativa

Escribid un poema (de entre ocho y catorce versos) en torno a la maternidad enfocado desde la perspectiva que os sugiera una reflexión más interesante (la elección de no tener hijos, el deseo de tenerlos, la esterilidad, el aborto, la reproducción asistida...).

\begin{tabular}{|l|l|}
\hline \multicolumn{2}{|c|}{ SESIÓN 5) POESÍA AUTOBIOGRÁFICA } \\
\hline Textos poéticos & $\begin{array}{l}\text { Preguntas para guiar la dis- } \\
\text { cusión literaria }\end{array}$ \\
\hline \multirow{2}{*}{$\begin{array}{l}\text { ¿De qué hablan estos poe- } \\
\text { mas? ¿Qué los diferencia de } \\
\text { los anteriores? Compartid al- } \\
\text { guna parte que os llame espe- } \\
\text { cialmente la atención, expli- } \\
\text { «Promesas que cumplir», Lanseros Jo o los tres elixires de Miss } \\
\text { cando el motivo. }\end{array}$} & $\begin{array}{l}\text { ¿Identificáis alguna de las } \\
\text { figuras estilísticas recopila- } \\
\text { das y descritas en el docu- } \\
\text { mento 1? En caso afirmativo, } \\
\text { localizadlas y explicadlas. }\end{array}$ \\
\hline $\begin{array}{l}\text { lotividades de búsqueda } \\
\text { Material complementario para enriquecer } \\
\text { la discusión }\end{array}$ & $\begin{array}{l}\text { Buscad información sobre la } \\
\text { documental } \\
\text { que y la obra de Aurora Lu- } \\
\text { to de la clase. }\end{array}$ \\
\hline
\end{tabular}


Documento 1. Clasificación y descripción de figuras estilísticas (Cerrillo y Luján, 2010).

Cartas a un joven poeta (Rilke, 2012).
Consignas de escritura creativa

Escribid un poema autobiográfico (de entre unos ocho y catorce versos) siguiendo el modelo de Luque o el de Lanseros. En el primer caso, podéis escribir a partir de la figura de un personaje literario (o varios) que os haya/n marcado.

\section{Conclusiones}

Una vez documentada la situación de la poesía y de la poesía escrita por mujeres en la Educación Secundaria (su exclusión de currículum y libros de texto), consideramos que el docente posee una responsabilidad (siquiera parcial) en la subversión de esta situación mediante la configuración de su propio canon de poetas. Ello, sobre la base del reconocimiento de que la constitución de cualquier canon posee un innegable componente ideológico y de la importancia de la proporción de referentes femeninos de realización intelectual y artística a los adolescentes en un momento especialmente relevante en sus procesos de construcción identitaria.

Este corpus, a nuestro juicio, habría de estar constituido por las poetas imprescindibles de otros tiempos, pero también por poetas contemporáneas. En este sentido, entendemos que también es responsabilidad del docente escoger de entre la poesía joven actual (cuya poeticidad es cuestionada, pero cuya acogida por parte de los jóvenes receptores es incontestable), aquella que permita, a un tiempo, acercar a los adolescentes al género poético, conectar con su sensibilidad e intereses y contribuir a su educación literaria, quizá tendiendo puentes, abriendo el diálogo e invitando a la comparación entre unos textos y otros. 
Por otra parte, en cuanto a la didáctica de la poesía, el abandono del historicismo, del exceso de teoría y del memorismo y la conexión, por el contrario, de la poesía con la realidad, inquietudes, pensamientos y sentimientos de los alumnos a través de una discusión literaria enriquecida con material complementario al poema, acompañada de propuestas de investigación documental y escritura creativa, parece instituirse como una buena opción, con mayores expectativas de éxito que otras empleadas con anterioridad. Huelga decir que este replanteamiento implica necesariamente una construcción compartida de significado en la que el docente deje de ser entendido como legitimador de interpretaciones.

En concreto, la propuesta didáctica presentada en esta línea, si bien no haya sido llevada a la práctica, consideramos que reúne ingredientes para convertirse en una buena opción, entre otras muchas posibles que habrían de diseñarse y sucederse, para contribuir a los objetivos ya explicitados: favorecer el acercamiento de los alumnos a un corpus de poesía escrita por mujeres en español que propicie una fértil reflexión en torno a tópicos de género, su formación en calidad de lectores críticos y una iniciación a la escritura poética.

\section{Referencias bibliográficas}

Adricaín, Sergio y Rodríguez, Antonio (2016), Escuela y poesía. ¿Y qué hago con el poema?, Cuenca, Ediciones de la Universidad de Castilla La Mancha.

Aguilar, Consol (2008), «Lectura, género, feminismo y LIJ», en Lenguaje y Textos, 28, págs. 113-128.

BALLeSTER, Josep (2015), La formación lectora y literaria, Barcelona, Graó.

BALlester, Josep e IbARRA, Noelia (2009), «La enseñanza de la literatura y el pluralismo metodológico», en Ocnos, 5, págs. 25-36.

Benegas, Noni (2017), «Ellas tienen la palabra: dos décadas de cambios», en Remedios Sánchez y Manuel Gahete (coords.), La palabra silenciada. Voces de mujer en la poesía española contemporánea (1950-2015), Valencia, Tirant Humanidades, págs. 387-400.

Berbel, Rosa (2018), Las niñas siempre dicen la verdad, Madrid, Hiperión. 
BollmanN, Stefan (2006), «Las mujeres, que leen, son peligrosas. Una historia ilustrada de la lectura desde el siglo XIII hasta el siglo XXI», en Stefan Bollmann, Las mujeres, que leen, son peligrosas, Madrid, Maeva, págs. 20-37.

BombINI, Gustavo (2008), «Volver al futuro: postales de la enseñanza literaria», en Carlos Lomas (coord.), Textos literarios y contextos escolares. La escuela en la literatura y la literatura en la escuela, Barcelona, Graó, págs. 135-147.

Bonet, Paula (2018), Roedores. Cuerpo de embarazada sin embrión, Barcelona, Penguin Random House.

Bordons, Gloria (2016), «Poesía contemporánea en el aula: experimentalidad, multimodalidad e interdisciplinariedad como formas de reflexión, creación y emoción», en Edetania, 49, págs. 45-60.

CABRÉ, M. Ángeles (2013), Leer y escribir en femenino, España, Aresta.

CÁNOvas, Ana (2018), «Cuerpos, sexualidad e identidad femenina. La poesía de María Sánchez (1989), Luna Miguel (1990) y Elvira Sastre (1992)», en Kamchatka. Revista de análisis cultural, 11, págs. 351-378.

Cerrillo, Pedro C. y Luján, Ángel (2010), Poesía y educación poética, Cuenca, Ediciones de la Universidad de Castilla-La Mancha.

Colomer, Teresa (1998), La formació del lector literari, Barcelona, Barcanova.

Decret 87/2015, de 5 de juny, del Consell, pel qual estableix el currículum i desenvolupa l'ordenació general de l'Educació Secundària Obligatòria i el Batxillerat en la Comunitat Valenciana.

Hermosilla, M. Ángeles (2011), «La poesía de mujeres en España: la búsqueda de una identidad», en Alfinge, 23, págs. 65-88.

JeAn, Georges (1996), La poesía en la escuela. Hacia una escuela de la poesía, Madrid, Ediciones de la Torre.

Jover, Guadalupe (2008), «Se está haciendo cada vez más tarde (Por una literatura sin fronteras)», en Carlos Lomas (coord.), Textos literarios y contextos escolares. La escuela en la literatura y la literatura en la escuela, Barcelona, Graó, págs. 149-178. 
LANSEROS, Raquel (2019), Matria, Madrid, Visor.

LASA, Begoña (2016), «La incorporación de las escritoras al currículo literario en la Educación Secundaria: una tarea pendiente», en Cuestiones de género: de la igualdad y la diferencia, 11, págs. 423-442.

LogroÑo, Isabel (2019), «Qué es poesía: género y nuevas poéticas productivas en la era de las redes sociales. Las poéticas de Elvira Sastre, Irene X y Loreto Sesma», en Signa, 28, págs. 843-866.

López NavajAs, Ana (2014), «Análisis de la ausencia de las mujeres en los manuales de la ESO: una genealogía de conocimiento ocultada», en Revista de Educación, 363.

LuQue, Aurora (2015), Personal y político, Sevilla, Fundación José Manuel Lara.

Mendoza, Antonio (1998), Tú, lector. Aspectos de la interacción texto-lector en el proceso de lectura, Barcelona, Octaedro.

Mistral, Gabriela (2019), Las renegadas. Antología, Barcelona, Penguin Random House.

MorianA, Gabriela (2017), «Educación en igualdad de género para prevenir la violencia machista», en Cuestiones de género: de la igualdad y de la diferencia, 12, págs. 267-286.

NAVARrete, María Teresa (2019), «Poesía española, mujer y nuevas tecnologías», en Signa, 28, págs. 245-269.

NúÑEZ, Gabriel (1998), «Antecedentes históricos: teoría literaria y didáctica de la literatura», en Antonio Mendoza (coord.), Conceptos clave en didáctica de la lengua y la literatura, Barcelona, Horsori, págs. 287-296.

Pérez Parejo, Ramón (2010), «Algunas voces femeninas en la poesía hispanoamericana actual. Guía didáctica», en Campo abierto, 29 (2), págs. 27-61.

PRADO, Josefina (2004), Didáctica de la lengua y la literatura para educar en el siglo XXI, Madrid, La Muralla.

Pulido, Genara (2020), «Musas de masas en las pantallas. Mujeres poetas españolas en el siglo XXI», en Signa, 29, págs. 733-761. 
Quiles, M. Carmen (2020), «Textos poéticos y jóvenes lectores en la era de Internet: de booktubers, bookstagrammers y followers», en Contextos educativos, 25, págs. 9-24.

Real Decreto 1105/2014, de 26 de diciembre, por el que se establece el currículo básico de la Educación Secundaria Obligatoria y del Bachillerato.

Regueiro, Begoña (2018), «Poesía juvenil pop: temas, recursos formales y estrategias para llegar al joven lector», en Ocnos, 17 (1), págs. 68-77.

Reyzábal, M. Victoria (2012), Canon literario y diferencia de género en la educación, Madrid, La Muralla.

RILKE, Rainer María (2012), Cartas a un joven poeta, Madrid, Alianza.

SÁnCHEZ GARCíA, Remedios (2017), «Cuando las poetas no tuvieron la palabra. El concepto de literatura sumergida en la poesía española (1950-2000)», en Remedios Sánchez y Manuel Gahete (coords.), La palabra silenciada. Voces de mujer en la poesía española contemporánea (1950-2015), Valencia, Tirant Humanidades, págs. 15-32.

SÁnchez García, Remedios (2019), "Canon escolar poético y pedagogía literaria en Bachillerato. Las escritoras invisibles en los manuales de literatura», en Pedagogía Social. Revista interuniversitaria, 33, págs. 43-53.

SERVÉN, Carmen (2008), «Canon literario, educación y escritura femenina», en Ocnos, 4, págs. 7-20.

SHOWALteR, Elaine (2010), «La crítica feminista en el desierto», en Nara Araújo y Teresa Delgado, Textos de teorías y crítica literarias: del formalismo a los estudios postcoloniales, Barcelona, Anthropos, págs. 381-404.

SOLUSTRI, Sofía Eva (2018), «La poesía amorosa en las redes sociales: la apropiación del lenguaje poético dentro y fuera del aula», en El toldo de Astier, 16, págs. 9-29.

Storni, Alfonsina (2020), Alfonsina Storni. Antología poética, Barcelona, Austral.

TusqueTs, Esther (2006), «¿Son peligrosas las mujeres que leen?», en Stefan Bollmann, Las mujeres, que leen, son peligrosas, Madrid, Maeva, págs. 10-19. 
ZALDívar, Raquel (2017), «Las actitudes de los adolescentes hacia la poesía, su didáctica y la educación emocional en la ESO», en Didáctica. Lengua y Literatura, 29, págs. 259-277.

VALVERde, Fernando (2017), «El boom de la poesía en español: Elvira Sastre», en Remedios Sánchez y Manuel Gahete (coords.), La palabra silenciada. Voces de mujer en la poesía española contemporánea (1950-2015), Valencia, Tirant Humanidades, págs. 413-427. 


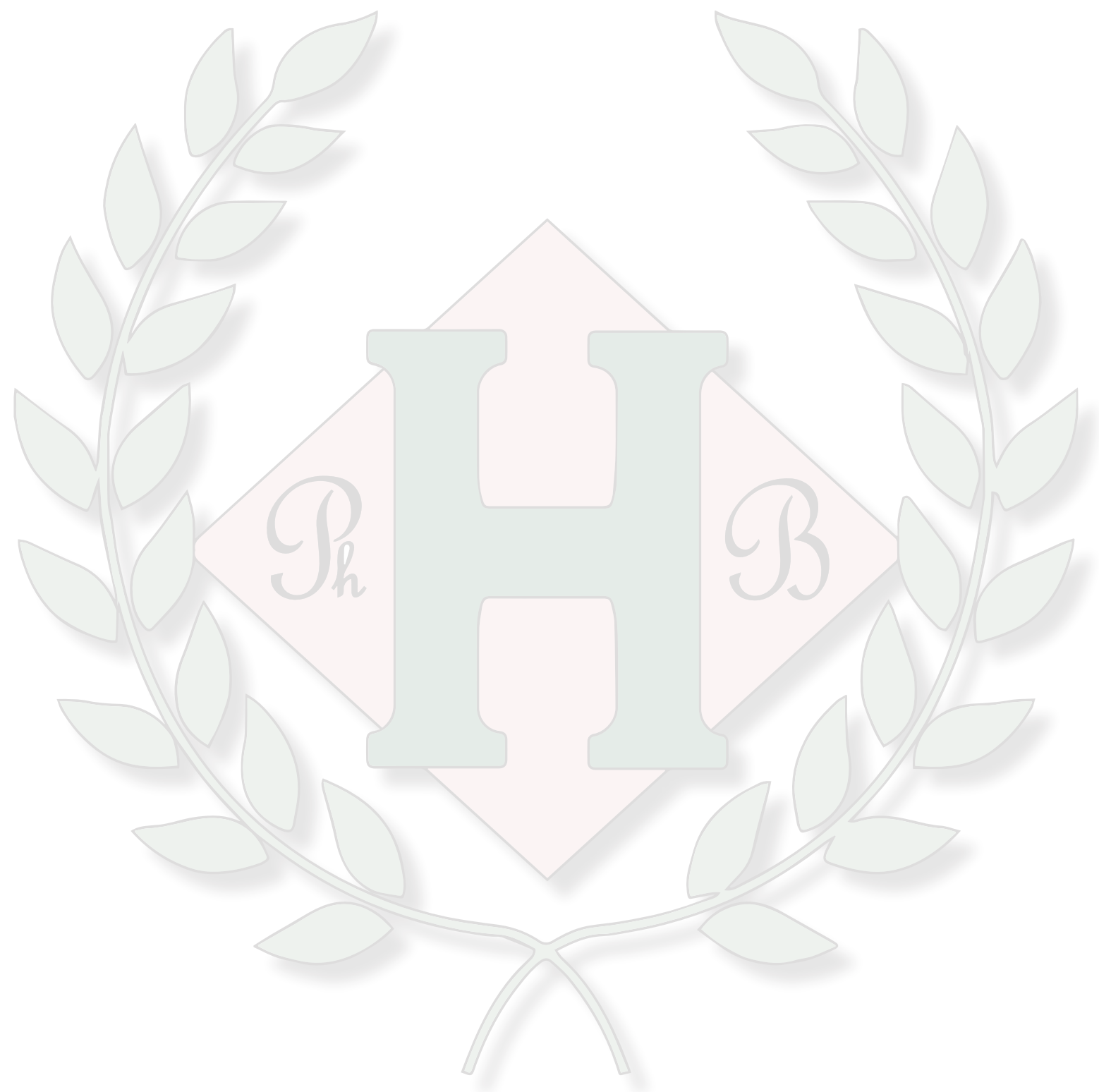

